\title{
Management by Principle for the Make-To-Order SME's
}

\author{
Shaladdin Muda ${ }^{1}$, Mohd Shaari Abd Rahman ${ }^{2} \&$ Fauziah Abu Hasan ${ }^{3}$ \\ ${ }^{1}$ Department of Management and Marketing, Universiti Malaysia Terengganu, Malaysia \\ ${ }^{2}$ Department of Accounting and Finance, Universiti Malaysia Terengganu, Malaysia \\ ${ }^{3}$ Department of Economics, Universiti Malaysia Terengganu, Malaysia \\ Correspondence: Mohd Shaari Abd Rahman, Department of Accounting and Finance, Universiti Malaysia \\ Terengganu, 21030 Kuala Terengganu, Malaysia. Tel: 60-9-668-4157. E-mail: shaari@umt.edu.my
}

\author{
Received: January 15, 2013 Accepted: February 24, 2013 Online Published: March 28, 2013 \\ doi:10.5539/ass.v9n4p227 URL: http://dx.doi.org/10.5539/ass.v9n4p227
}

\begin{abstract}
This paper describes a new model developed for make-to-order (MTO) sectors namely SHEN Principles, which aims to fill a gap in the world class manufacturing (WCM) literature that concentrates on the characteristics of the larger traditional make-to-stock (MTS) sector. Using evidence from the literature, especially the MTO literature and the more comprehensive WCM models, a new principle was devised. This was then modified in the light of case study evidence collected from the four MTO companies ranging from small to medium size MTO companies. The model presented in this paper known as "SHEN Principles", comprises of fourteen principles and categorized into four main sections for ease of reference such as generate enquiries/sales, operations and capacity, human resources and general continuous improvement. SHEN principle is a descriptive approach, with a five point progressive scale for each principle. Level one is the first step on the road to improvement and level five relates to current best practice performance. Its intended purpose is to aid MTO companies to determine their strengths and potential areas for improvement so that they can continue to be competitive in the future.
\end{abstract}

Keywords: SHEN principles, make-to-order, management

\section{Introduction}

Much of the literature on 'world class manufacturing' (WCM) has concentrated on the 'make-to-stock' (MTS) sector (Aslan, Stevenson, \& Hendry, 2012; Muda \& Caroline, 2003; Muda \& Caroline, 2002). Little attention is given on how to apply world class concepts in the 'make-to-order' (MTO) sector. This laxity may be due to the assumption that this sector can be treated in the same way as the 'make-to-stock' (MTS) sector. However, 'make-to-order' companies operate differently from 'make-to-stock'. The business is based on producing a special kind of product to customer specifications rather than producing standardised parts to stock. The production only starts when the customer places an order. To win an order, the company has to compete with other companies on the basis of price and the delivery date. On the other hand, make-to-stock companies produce and place their product in inventory before receiving a customer order. The customer may purchase the product directly from inventory at a retail outlet or at the factory distribution centre. Figeure 1 compares some of the characteristics of the two groups MTO and MTS as set out by Aslan et al. 2012, Muda \& Caroline (2003; 2002), Hendry, Wilson, Kingsman, Worden, \& Mercer (1992) and Amaro, Hendry, \& Kingsman (1999). 


\begin{tabular}{|c|c|c|}
\hline $\begin{array}{l}\text { MAKE TO ORDER } \\
\text { COMPANIES }\end{array}$ & CHARACTERISTICS & $\begin{array}{l}\text { MAKE TO ST OCK } \\
\text { COMPANIES }\end{array}$ \\
\hline Few standard products & $\begin{array}{l}\text { Product or customer } \\
\text { families }\end{array}$ & Product/family focus \\
\hline Few regular customer & Customers & Hav ing regular customers \\
\hline Many suppliers & Suppliers & Few suppliers \\
\hline $\begin{array}{l}\text { Multi-task machinery and } \\
\text { flexible workforce }\end{array}$ & Resources & $\begin{array}{l}\text { Specialist machinery and } \\
\text { workforce }\end{array}$ \\
\hline $\begin{array}{l}\text { Demand is volatile and } \\
\text { can rarely be predicted }\end{array}$ & Product Demand & $\begin{array}{l}\text { Demand for standard } \\
\text { products can be forecast }\end{array}$ \\
\hline $\begin{array}{l}\text { Based on receipt of } \\
\text { customer orders. Cannot } \\
\text { be planned in advance. }\end{array}$ & Capacity Planning & $\begin{array}{l}\text { Based on forecast } \\
\text { demand. Planned well in } \\
\text { advance. Adjusted later if } \\
\text { necessary }\end{array}$ \\
\hline $\begin{array}{l}\text { Vital for customer } \\
\text { satisfaction. Agreed with } \\
\text { customer }\end{array}$ & Production lead times & $\begin{array}{l}\text { Unimportant to customer. } \\
\text { Can be set internally }\end{array}$ \\
\hline $\begin{array}{l}\text { Negotiated with customer } \\
\text { before production } \\
\text { commences }\end{array}$ & Prices & Fixed by the producer \\
\hline
\end{tabular}

Figure 1. A comparison of MTO and MTS companies

The aim of this paper is describe the use of SHEN principle for the MTO SME sector. The new principle, which has been named the "SHEN" principle, is contingent on the company type. This paper describes the current version of the principle and the research process followed to develop it (Muda \& Caroline, 2002). This included deductive research whereby the initial principle was developed using literature evidence and past experience of the authors, followed by inductive research in which case study data was collected from one MTO SMEs in the Northwest of England in order to develop the principle further. The principle aims is to help companies determine which performance improvements are needed and how to prioritise them in the race to be world class.

The case study research was exploratory in nature and aimed to gain further insights into the issues and solutions that are pertinent to MTO SME's. This was achieved by first looking at the current operations performance and practices in each of the companies, and exploring with personnel any projects that had been undertaken but had not lead to satisfactory implementations. By comparing this data with the initial SHEN principle, areas of strength and areas of weakness were postulated along with a list of potential improvements. These findings were then discussed with company management, to determine whether they agreed with the assessment of the company and the ideas on how MTO companies should seek to remain competitive in the future. The results suggested that some of our initial assumptions needed to be modified. For example, it was initially assumed that MTO companies should aim for a high level of worker flexibility, higher even than is achieved in the MTS sector, given the high variety of customized products. However, it was concluded that training is expensive in this highly skilled sector and that it is often only necessary to have a few workers trained for particular processes. Therefore, a training need matrix should be devised which establishes the number of people that need to be trained in each skill. Any further training is unnecessary and will soon be wasted as, without the experience of using the new skill, it is likely to be quickly forgotten. Thus the current version of the SHEN principle presented here incorporates changes to some of the assumptions in the light of the case study evidence.

\section{SHEN Principles}

The SHEN principle contained 14 principles, each comprising 5 steps. Level one is the first step on the road to improvement and level five relates to current best practice performance. In order to use the principle, it is intended that companies will assess their current practice and performance to determine which levels of achievement they have attained for each principle. This should lead to a set of company strengths and a set of 
potential company improvements. The management will then need to consider the latter carefully to determine how to implement them in their particular manufacturing environment.

Table 1. The detailed steps of the SHEN model

\section{SHEN PRINCIPLES
Generate enquiries/sales}

1. Integrate the functions of production and marketing in all processes;
Breakdown points - 1 to 5 ascending scales

1. Initial understanding between production and marketing;

2. Production and marketing functions work together in responding to customer enquiries;

3. Having a systematic data base system to enable MTO companies to respond to customer enquiries;

4. Achieve $50 \%$ reduction in time to respond to customer enquiries;

5. Understanding its competitors and having a systematic method for calculating price and delivery lead-time (i.e. strike rate matrix).

2. Design for products, processes and improved supplier

relationships;

3. Collaborate with customers,

\section{Operations and capacity}

4. Simplify the shop floor;

5. Seek simple, flexible, movable, low-cost equipment in multiples;
1. Train employees in understanding all the product specifications, product design rework and purchasing process/ knowing their suppliers; 2. Having a computerised design database with designs that can be altered for new orders;

3. Having a minimum number of parts, forgings or suppliers for each product;

4. Achieve 30\% "repeat business" which makes it possible to establish partnerships with some of the suppliers;

5. Achieve 50\% "repeat business".

1. Having good communication among employees, a common understanding of organisational objectives and customers needs;

2. Establish a personal relationship between employees and customers;

3. Getting customer representatives on the project;

4. Company helping the customers define their needs into product specifications and design;

5. Helping the customers meet their goals, rather than providing customer's wants.

1. Improve visibility, use simple storage systems to reduce search times;

2. Improve locations of raw materials, WIP etc. to cut distances for movement of materials and tools;

3. Train shop floor employees on the importance of using the storage systems and of taking responsibility for their own housekeeping;

4. Implement housekeeping so that work areas are clean as well as ensuring that the storage systems are properly used;

5. The operator takes over his own housekeeping.

1. Establish a policy to purchase and maintain equipment as required to meet goals;

2. $30 \%$ of equipment is highly flexible/movable;

3. $50 \%$ of equipment is highly flexible/movable;

4. $80 \%$ of the equipment is highly flexible/movable;

5. $99 \%$ of the equipment is highly flexible/movable. 
6. Improve scheduling and workload control to cut flow times;

7. Cut the start up/ changeover time and improve preventive maintenance;

8. Improve information flow;

\section{Human resources}

9. Make rapid improvements in skills and flexibility;

10. Have systematic rewards, recognition and monetary payment;

11. Everybody involved in change and strategic planning - to achieve a unified purpose;
1. Train associates in job shop sequencing, queuing limitation, workload control, handling priority;

2. Having a practical, simple and easily implemented workload control or scheduling system which can be modified as priorities change;

3. Having a computerised database system for scheduling/workload control;

4. Achieving average reduction of flow time by $30 \%$;

5. Achieving average reduction of flow time by $50 \%$.

1. Train associates in set-up/ changeover reduction and basic preventive maintenance;

2. Achieving $20 \%$ average reduction in set-up/ changeover time;

3. Operators can take over their own preventive maintenance;

4. Achieving 30\% average reduction in set-up/changeover time;

5. Employees achieve 50\% reductions in set-up/ changeover times across all processes.

1. Job priorities are clearly understood by all and everyone is working to the same plan;

2. Having a systematic method to communicate the plan including manual systems such as a planning board or 'work to lists' produced by an appropriate software package;

3. Having information about quality, cost, orders, delivery, and design that is readily available anytime to all in the factory;

4. Workflow, quality, internal scheduling and labour transactions cut by $25 \%$;

5. Internal transactions cut by 50\% and 50\% of external transactions are done by fax/Internet/ EDI.

1. Implement a training programme for all associates to increase relevant skills;

2. $80 \%$ of associates are flexible in skills and able to work on any machine;

3. $99 \%$ of associates are flexible in skills and able to work on any machine;

4. Experts teach operators to do repairs; downtime cut by $50 \%$;

5. Operators become technicians; downtime cut by $80 \%$.

1. Having a systematic performance appraisal system;

2. Systematic public recognition/celebration of achievement;

3. Variety of low-cost awards to both teams and individuals;

4. The company is investing in employees via training, cross training, cross careering;

5. The company reward for skills/knowledge; team/unit bonuses.

1. Having strategic planning;

2. Sharing information and records with shop floor employees;

3. The frontline employees/teams/supervisors use process analysis, plot trends; 
4. Encourage employees to make suggestions to improve the process;

5. The company gains the involvement and commitment of customers in their strategic plan.

\section{General continuous}

12. Improve quality and implement appropriate performance measures;
1. Establish a culture that supports continuous improvement in all processes;

2. Practice the principles of quality;

3. Training in universal customer wants: quality, speed, flexibility or value $(Q S F V)$;

4. $Q S F V$ are dominant performance measures;

5. Second order performance measures (e.g. labour productivity, variance) no longer managed.
13. Gather customer feedback and benchmarking;

4. Promote/market/sell every improvement.
1. Gathering customer-satisfaction data, review complaints and make continuous improvement on products and services;

2. Gathering data on future customer needs;

3. Gathering competitive samples and best practice data;

4. All associates involved in customer/ competitive best practice;

5. The company implement full-scale benchmarking for its processes.

1. Having good advertisements with effective placing (newspaper, magazine, etc.) for the target customers;

2. Positive QSFV trends featured in selling, bids, proposals, ads;

3. Registration; certifications; local awards (ISO-9000, Ford Q1, state award);

4. Global/national awards (e.g., Baldrige);

5. Reverse marketing: Out of strength, you choose whom you sell to.

\section{The Five Step Improvement Scale}

The SHEN principle as shown Table 1 groups its principles into 4 categories, each containing several inter-related principles. The categories are intended to assist the company to track achievement based on related activity. In some cases, the grouping may also help the company to decide how to prioritise the changes needed in its improvement program. The main objectives of the first category, "generate enquiries/sales", are (a) to provide a quick response to customer enquiries (b) to translate customer enquiries into product specification and design, and (c) to make the necessary plans to ensure that operations can meet the customer's goals. Under the second category, "operations and capacity", the shop floor operation is organised to help ensure a steady flow of materials. Activities include determining lead-time, set-up time, preventive maintenance, housekeeping and scheduling. The next category, "human resources", refers to the improvement of the company's workforce and finally the fourth category of the SHEN principle, "general continuous improvement", covers the aspects of quality and performance measures, benchmarking and marketing.

It is important to note here that the five steps are not intended to be used as part of a scoring system, as has been the case in previous models such as Schonberger (1996). Indeed, it could be argued that scoring companies is not possible using any WCM concept as they are not precise enough to be used for such judgmental purposes. Rating or scoring is only possible if the numbers of the steps represent equal increments of the attribute being measured (e.g. the Likert, Thurstone scale). In such a case, the differences can be compared; for example the difference between 1 and 2 is the same as between 2 and 3. This makes it possible to compute an arithmetic mean from the scores and the data is referred to as an "interval scale". However in the SHEN principle, it is not possible to distinguish the exact value/ amount of difference between the steps in each principle. Aaker, Kumar \& Day (1995) describe scales of this type as "ordinal" rankings. According to The New Webster Encyclopedic Dictionary of the English Language (1997), an ordinal ranking refers to any numbers that express degree, quality or position in a series, as first, second and third etc. Aaker et al. (1995) claimed that "ordinal" rankings provides 
information on the differences between the improvement activities but without indicating the exact amount of difference. Therefore it is not possible to compute a mean ranking in ordinal scales because the differences between ordinal-scaled values are not necessarily the same (Aaker et al., 1995). For example being in level 4 in one principle doesn't mean being twice as good as level 2 .

\section{Detailed Explanation of the SHEN Application}

This section demonstrates the application of SHEN in the furniture industry in Lancashire England. The main aim of this section is to identify the level of attainment for each principle using the SHEN in the company below.

The company, employing 16 people, is a privately owned MTO company in the furniture industry. It was established in 1976. Based in Carnforth Lancashire, the company is involved in manufacturing a wide variety of bespoke furniture for home kitchens, bedrooms and shops. The company orders came from two main sources; trade customers/retail and the individual customers. The company has twelve regular trade customers. However, the product is still bespoke furniture, even though the company is supplying to trade/retail customers. This is because all the products are for individual end customers designed for specific kitchens, bedrooms and shops. The Company is considered to be a very small company consisting of $£ 0.25$ million of assets and approximately $£ 0.6$ million turnover per year.

\subsection{Initial Assessment}

The areas of strength are shown on the left-hand side of Figure 2. It was found that administration, sales and production are located on the same floor. Communication during the enquiry process is therefore very easy and many quotations can be done very quickly. "Usually we respond within 2 to 3 days...if asked we can do it within a couple of hours," claimed the Managing Director (one of the company's owners). Window based

Excel is used by the company to store information regarding customer enquiries, materials, orders and deliveries. Therefore it was concluded that the company is good on principle 1, "integrate the function of production and marketing in all processes" as shown by the first left arrow in Figure 2.

Principle 4, is to "simplify the shop floor". The company also has a good storage system. They are using a very large amount of timber every year. The storage area is necessary because it is more economical to buy timber from the two suppliers in large quantities. When timber arrives, it is unloaded from the wagon and placed on separate racks based on its code number. Besides timber, "mouldings" are also placed in the storage area on the labelled racks. "Mouldings" are pieces of wood especially made into standard shapes that are regularly needed. All of these raw materials are easy to find when needed by the shop floor workers.

The third area of strength comes from principle 5, "seek simple, flexible, movable, low cost equipment in multiples". "In general they are small and easy to move around", claimed the Managing Director. Therefore it was concluded that the company is good on principle 5, flexibility of equipment.

The fourth area of strength is derived from principle 7, to "cut the start up/ changeover time and improve preventive maintenance". This strength is mainly concerned with machine maintenance. "We don't have many breakdowns... The machinist keeps monitoring the machines", claimed the Managing Director.

The next area of strength comes from principle 8 , information flow. Computers are used extensively within the company. It has cut down many internal transactions (administration records, sales, purchasing, etc.) and more than $50 \%$ of the office transactions are by computer. In terms of external transactions, most correspondence is carried out using e-mail and the fax machine.

The sixth area of strength comes from principle 9, which relates to the fundamental difference between MTO and MTS, the inherent flexibility of the workforce. Skill level and flexibility are already high in this company. In order to give the machinist more proficiency, training on general courses like management, finance and computer handling are given to employees at the North Lancs Training Group, Accrington. Minor breakdowns are not a problem for the company. In fact in $75 \%$ of the cases the repairs are done by the workers. However in a major breakdown, the company will call in the machine supplier or an outside company to deal with it. The seventh and final area of strength is with respect to principle 12, "improve quality and implement appropriate measures". The Managing Director claimed that the company has had quality implementation in their products for a long time. He claimed that quality is very important and needs to be $100 \%$ as far as the customer is concerned, otherwise the company cannot sell anything. The Managing Director also claimed that the employees always know the "value" the customer wants. The customer wants "quality and flexibility" and the company is providing these values to satisfy its customers. However the company hasn't got any quality accreditation. 


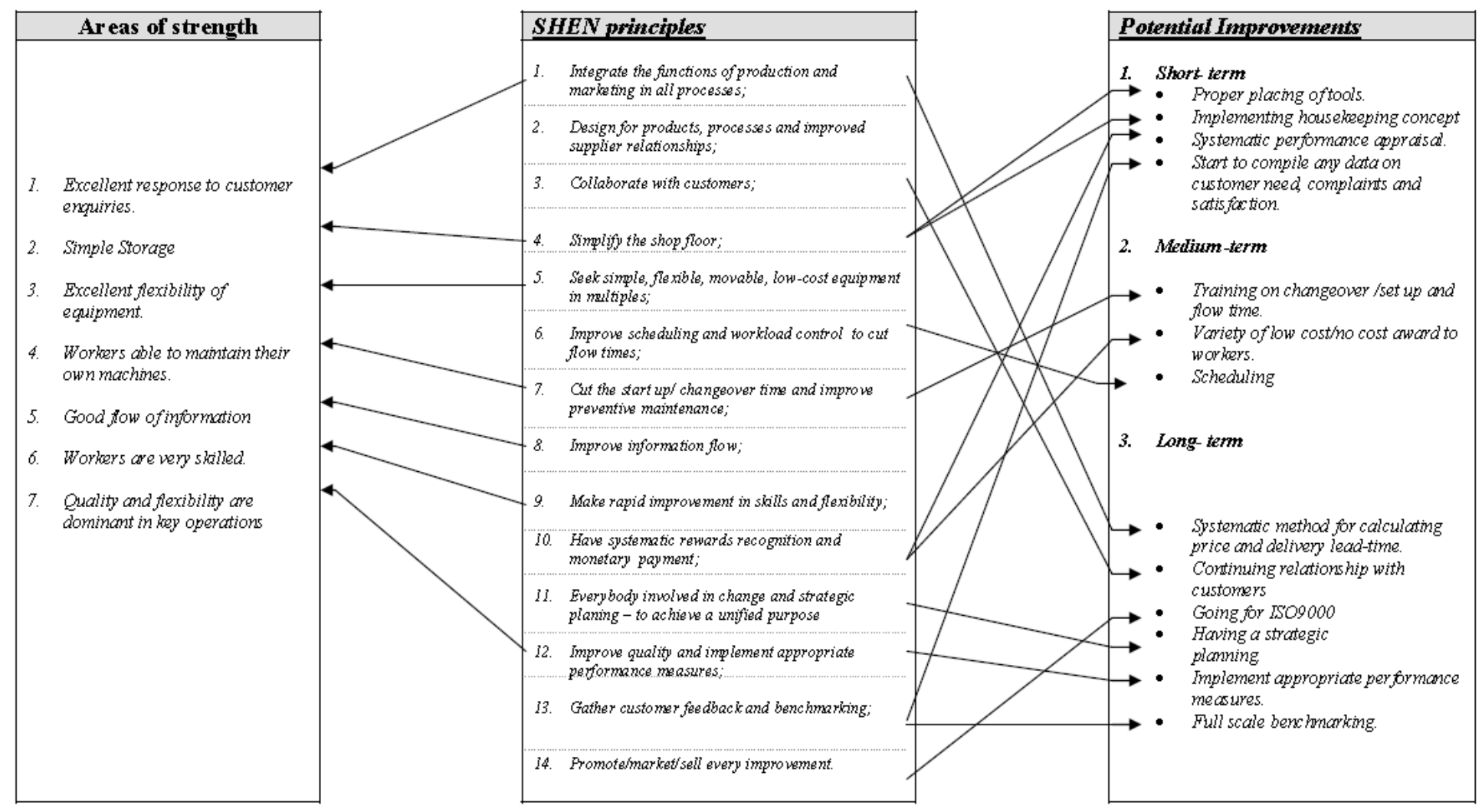

Figure 2. Summary - initial assessment for the company using the SHEN model

Figure 2 presents a summary of the improvement activities for various time periods. The first short-term issue is with respect to principle 4, the placing of tools and the implementation of the "housekeeping" concept. The tooling system is still a problem with this company as time is often wasted searching for the right materials when needed. "It is not only the tools for the machine .... also the hand tools", claimed the machinist. Tidiness is the second issue that the company needs to consider. The whole factory looks untidy because small pieces of wood and wood dust are everywhere on the shop floor. There is a janitor responsible for cleaning the areas in the evening but nobody is responsible to clean the shop floor during the day.

The third issue comes from principle 10, to "have systematic rewards recognition and monetary payment". The company hasn't done any performance appraisals, although the management claimed that they are constantly monitoring the employees informally.

The fourth and final issue under short-term improvements is derived from principle 13, "gather customer data feedback and benchmarking". At present, the company hasn't got any data on customer needs and complaints. Therefore it was concluded that the company should start compiling data regarding customer needs, complaints and satisfaction.

For the medium-term improvements, the first issue comes from principle 7, "training employees to cut set up and flow-time". The company claimed that they have already achieved a 10 to $20 \%$ reduction in the set up time. But the Managing Director argued that this is not enough. He agrees that set up time needs to be improved. "Running time cannot be improved, but we can do it on set-up", claimed the Managing Director.

Second is principle 10, the issue of rewarding workers. For the time being there have been no bonuses, no recognition and no incentives given to employees. It was concluded that the company should start implementing the reward system to value its employee's contribution.

The last medium-term issue as derived from principle 6 is scheduling. Only one person is responsible for scheduling the jobs. He prioritises and translates orders into a timetable for all employees. He does this based on his experience in determining which job goes to which machine. But relying on one person to do this scheduling is risky, because during his absence, no other person can do this job as well as he does. Therefore one or more 
people need to be trained in scheduling. A simple computer package (e.g. Excel) could be used to assist in scheduling because the number of orders is not very large.

Regarding the long-term issues the right-hand side arrows show that there are four potential improvements identified. The first issue is a systematic method for calculating price and delivery lead-time. Even though the company is good in this category, the enquiry/estimation process can still be improved by gathering data on previous bids. Information on previous bids either won or lost could be used to help the company to evaluate bids better in the future.

The next issue is with respect to principle 3, to have a continuing relationship with its customers. At present the company has appointed a part time agent to deal with customers. His responsibility is to find new sales, make personal contact, and regularly get in touch with customers. He receives commission based on the sales he makes. $\mathrm{He}$ is also responsible for compiling any information regarding customer complaints because he deals direct with the customers (i.e. trade customers). Nevertheless this person only works part time. He does not have enough time to do all the work. Therefore the information was not properly gathered. Due to this reason it was concluded that the company should initiate more effort to establish persistent contact with its customer.

The third issue is derived from principle 12, is to go for ISO 9002. At present, the company does not have any accreditation for its product. The fourth issue concerning principle 11 is on strategic planning. The company does not have a proper future plan. When the shop floor workers were asked about the company's plan, nobody could give an answer. "I am not informed about the company's plan.... I don't know", claimed one machinist. The fifth issue relates to principle 12, which is to implement appropriate performance measures. The company measurement is simply by profit and sales growth. The final issue which comes from principle 13, is benchmarking. At the moment, the company hasn't performed any benchmarking.

\subsection{The Company Response to the Initial Assessment}

For the most part the initial assessment, on the areas of strength and areas for improvement, were agreed by the Managing Director. However, there were a couple of areas of disagreement as shown in the Table 2. During this discussion the manager also provided some sample documents including purchasing orders, working schedules, product drawings and the company's finished products. This section will explain the findings of this discussion.

Table 2. Company response to the initial assessment

Issues highlighted by case study evidence at the first set of visits.

Company response to the issues raised in the report

\section{STRENGTHS}

Excellent response to customer enquiries.

Agreed.

Simple storage.

Agreed.

Excellent flexibility of equipment.

Agreed.

Workers are able to maintain their own Agreed.
machines.

Good flow of information.

Agreed.

Workers are very skilled. Agreed.

Quality and flexibility are dominant. Agreed.

\section{SHORT-TERM POTENTIAL IMPROVEMENTS}

Proper placing of tools.

Implementing housekeeping concept.

Systematic performance appraisal.

Compile data on customer needs, complaints and satisfaction.
Agreed.

Agreed.

Disagreed - no prospect of promotion.

Disagreed- time consuming to gather formal data.

\section{MEDIUM-TERM POTENTIAL IMPROVEMENTS}

Training on cut changeover/set up.

Variety of low cost/ no cost awards to workers.

Scheduling.
Agreed.

Disagreed - difficult for a small company.

Agreed. 


\section{LONG-TERM POTENTIAL IMPROVEMENTS}

Systematic method for calculating price and delivery lead-time.

Continuing relationship with customers.

Going for ISO 9000.

Having strategic planning.

Implement appropriate performance measures

Full scale benchmarking.
Agreed.

Better than initially understood. $90 \%$ of the business with regular trade customers.

Not unless driven by the customers.

The company performs this but not well documented. Some key personnel are informed.

Disagreed - sales growth and profit are preferable.

Agreed would be difficult, but worthwhile.

The Managing Director agreed that the workers have to spend time walking around searching for tools. One possibility discussed was for the company to identify specific tools needed in certain areas on the shop floor, and make sure that the tools reside in that place only. The management might then impose a policy to prohibit moving or lending out tools. Another possibility is to purchase more tools so that the time spent searching for tools is reduced.

On the second issue, the company claimed that the idea of "housekeeping" is possible, although there was some debate about how this could be achieved. Initially it was thought that implementation of housekeeping should be based on assigning areas to workers (area centred) but then agreed that it could be achieved by being machine centred. That is, that anybody using the machine should be responsible for cleaning it. The company claimed that assigning the new responsibility to the employees should not be a problem because it is written into the employee's contract.

Regarding systematic performance appraisal, the Managing Director argues that this idea is not suitable for a small company. He believed that formal appraisal is worthless because there is no prospect of promotion. There must be something resulting from formal appraisal. Besides, he felt that assessing people could create fear among workers. The company also hasn't got enough people to handle the formal appraisal task. However, the Managing Director claimed that he was constantly in touch with shop floor people, providing informal feedback on their performance.

The final issue under short-term improvement is on the gathering of data on customer complaints. The company does have regular contact with some main customers. The contact may be in terms of an interchange of ideas on product improvement, or on feedback. The manager agreed that he hasn't got any formal data on customer needs, complaints and satisfaction. The company doesn't intend to gather information using formal approaches because it would be too time consuming.

For medium-term improvements, one of the suggestions is training employees to reduce machine set up. Training for reducing set up is already given by the company through on-the-job training. However the Managing Director agreed that they are still behind in terms of cutting set up time. Through discussion he agreed that having enough tools and keeping them in their proper places could also reduce the set-up time. Another possibility is to buy more sophisticated small machines with a Computer Numerical Control (CNC) set up, which is very fast. It is linked to a computer, and the machine operator only needs to insert the specific/correct tools as instructed by the computer, which will take only a few minutes. However, CNC machines are acceptable if the machine is still flexible and movable, but should be questioned if this is not the case. Here, there may be a need to find a balance between the need for faster set-ups and movable machinery.

However the Managing Director does not agree with the second idea on "variety of low cost/no cost awards to workers". He felt that this idea is difficult to translate into practice. He assumed that the workers are all equally skilled and therefore it is quite difficult to assess the performance of any individual worker, which also may cause unfairness.

In terms of scheduling, the company claimed that they are using Excel to ease the process which is better than initially thought. The company is using backward scheduling from the promised delivery date and a simple Gantt chart to make plans for the jobs. However, the company is still relying on one person to do the scheduling, and the use of EXCEL does not include any capacity planning/workload control.

For long-term improvements, the first issue is on a systematic method for calculating price and delivery lead-time. Though the company is doing well in this category the estimation process could still be improved by 
gathering data on previous bids. The company agreed that having a systematic method of estimation could be a great help to the company. However the company hasn't got the manpower to gather the data. At the moment, the company does have a part time salesperson who is responsible for marketing though. His job is to get feedback from customers on price and also to know where the company stands in the market place.

The next issue is concerned with having continuing relationships with its customers. Initially it was believed that $40 \%$ of the company business was with regular customers. Nevertheless the company did better than expected. It was found that ninety-percent of the dealings are with regular trade customers. In fact this idea should be included under the company's strengths.

The third issue is going for ISO 9000 recognition. The Managing Director was not interested in going for ISO certification. He felt that accreditation was not important for this kind of business. There were many constraints such as labour, finance and time. Besides the customer did not require it. "We are not interested unless it is driven by customers", claimed the Managing Director.

Regarding strategic planning, the company also did better than initially thought. The manager claimed that the company has a future plan, but it is not well documented. Yet, some key personnel were informed about the company future plan. This includes adopting a new software system, increasing more key people and buying new machinery.

In terms of performance measures the management claimed that turnover and profit were already a good measurement to indicate its company's growth. The management was not interested in other kinds of measurement system (i.e. problem solving, defect rate reduction) because implementing these kinds of measurements requires an increase in labour time which is a major constraint for a company of its size.

The fifth and final issue is on benchmarking. The management believed that the implementation process is complex because it was difficult to find a suitable company to benchmark with. The main device used by the company is asking the customers to compare prices in relation to its competitor prices. However, the company also sends workers to visit other factories when appropriate opportunities arise.

\subsection{Final Assessment}

Table 3 summarises the case study evidence for the company, including an indication of the levels attained for each principle.

Table 3. Final assessment for the company

\begin{tabular}{|c|c|c|c|c|c|c|}
\hline \multirow[t]{2}{*}{ Principle } & \multicolumn{4}{|c|}{ Levels attained } & & \multirow[t]{2}{*}{ Comments } \\
\hline & 1 & 2 & 3 & 4 & 5 & \\
\hline Principle 1 & / & I & 1 & I & & $\begin{array}{l}\text { - } \quad \text { Very good response to customer enquiries. } \\
\text { - } \quad \text { Small size eases communication. } \\
\text { - } \quad \text { Window based excel is used to store information. }\end{array}$ \\
\hline Principle 2 & I & l & / & I & I & $\begin{array}{l}\text { - Company is responsible for design, specification, and } \\
\text { purchasing. } \\
\text { - Machinists can easily understand the specifications. } \\
\text { - As well as new designs, many existing designs are also } \\
\text { displayed in the showroom. Customers can pick up any design and } \\
\text { decide variations. }\end{array}$ \\
\hline Principle 3 & / & l & l & l & & $\begin{array}{l}\text { - Appointed a part time agent to deal with customers. } \\
\text { - Higher points may not be appropriate because there are not } \\
\text { sufficient employees to have relationships between employees and } \\
\text { customers. }\end{array}$ \\
\hline
\end{tabular}

- Difficult to have customer representatives on the project. 
Principle 4

Principle 5

Principle 6

Principle 7

Principle 8

Principle 9

Principle 10

Principle 11

Principle 12
- $\quad$ Agreed that issues like proper placing of tools and implementing the housekeeping concept need to be improved.

- Discussed the possibility of buying more tools so that no one needs to borrow them and make sure tools reside in one place only.

- $\quad$ For housekeeping, it needs to be machine centred and not area centred - therefore the person who used the machine needs to clean it.

- Assigning new responsibilities is not a problem - the contract states the workers will do anything the company have written.

- Most machines are relatively small and simple and maintained by the workers.

- The workload is not high .

- Using a simple Gantt Chart - using backward schedule.

- No specific training is given to do the machine set-up.

- Admit that the company is still behind in cutting set up.

- Everybody is responsible for maintenance.

- The management agreed that this is the key area for them to make changes.

- Several possible alternatives identified to reduce set up - either buying more $\mathrm{CNC}$ machines or buy cheaper machines and buy more tooling.

- A daily list of working progress is provided using excel printouts - which contain the customer number, order number, customer name and the progress code. Progress code assigned from no. $0-11.0$ is not started and 11 is dispatched.

- Many office transactions are computerised.

- Most external transactions are by fax.

- Currently in the middle of installing new software to link CAD/CAM design directly to the shop floor to shorten the information flow.

- Machinists are expertly skilled.

- $75 \%$ of breakdowns repaired by the machinist.

- Verbal appreciation by the Director.

- Performance appraisal is worthless because there is no prospect of promotion in small companies.

- Assessing people creates fear among workers.

- Low cost/no cost award is not worthwhile- workers are equally skilled; unfairness etc.

- Encourage suggestions.

- The management argues that the company is in trouble if they can't think 5 years ahead.

- Shop floor workers know the level of quality needed by customers.

- Every body is responsible for the quality of their products.

- $\quad$ Performance measures- sales growth and profit. 
Principle 13

Principle 14
- Does have a regular contact with some key customers.

- Interchange of ideas on product improvement and feedback.

- Does not intend to gather information in formal ways informal approach is better with the number of customers they have at present.

- But agreed that a more formal approach may be needed as the number of customers grows.

- Full scale benchmarking is difficult.

- Many sales are due to recommendations.

- Selling quality and flexibility.

- Unless driven by customers, can't see any point attaining ISO 9002.

\section{Conclusion}

The "SHEN" model, groups its principles into 4 categories, each containing several inter-related principles. The category titles are generate enquiries/sales, operations and capacity, human resources and general continuous improvement. Each category comprises of three principles with the exception of operations and capacity, which has five. The first few principles from the lists 1, 2, 3, 4 and 6 contain most of the material relating to MTO companies that tends to be missing from previous WCM models in the literature. These include integration of the functions of production and marketing, the product design process, customers' relationships and so on. The remainder of the principles are built/modified from generic, universalistic literature that is aimed at all manufacturing companies. The latter include issues on performance measurement, benchmarking, housekeeping, preventive maintenance, human resources and so on. However, even where this type of material is present, the principles have been carefully tailored to suit the high variety, low volume MTO environment.

\subsection{Areas for Further Research}

The following issues represent potentially interesting continuations to the present study:

1) At the moment the SHEN principle are not given in any particular priority order. Instead the principle just identifies the set of issues. This is because it was felt that before a priority ranking could be found it is important to make sure that the list of possible improvements is comprehensive. Further research is needed to enable companies to determine which changes to make first and whether to make changes simultaneously or sequentially.

2) It is essential that the principle should be useable by companies without the need for expert interpretation. Thus, future research will also involve the investigation of alternative methods of principle presentation, including the possibility of using a workbook that can be used by company personnel to devise their own improvement programmes. In particular, such a workbook should provide some type of cost/benefit analysis so that companies can prioritise the various improvement options and allocate their limited resources to the best effect.

\section{References}

Aaker, D. A., Kumar, V., \& Day, G. S. (1995). Marketing Research. John Wiley and Sons Inc., New York.

Amaro, G., Hendry, L., \& Kingsman, B. (1999). Competitive advantage, customisation and new taxonomy for non make-to-stock companies. International Journal of Operations \& Production Management, 19(4), 349-371. http://dx.doi.org/10.1108/01443579910254213

Aslan, B., Stevenson, M., \& Hendry, L. (2012). Enterprise resource planning systems: An assessment of applicability to make-to-order companies. Computer in Industry, 63(7), 692-705. http://dx.doi.org/10.1016/j.compind.2012.05.003

Clifford, J. P. (1999). The collective wisdom of the workforce: Conversations with employees regarding performance evaluation. Public Personnel Management, 28, 119-156.

Deshpande, S. P., \& Damodar, Y. G. (1994, April). HRM practices in large and small manufacturing firms: a comparative study. Journal of Small Business Management, 49-56. 
Garsombke, T. W., \& Garsombke, D. J. (1989). Strategic Implications facing small manufacturers: The linkage between robotisation computerization, automation and performance. Journal of small business management, 27(4), 34-44.

Hendry, L. C. (1998). Applying world class manufacturing to make-to-order companies: Problems and solutions. International Journal of Operations and Production Management, 18(11), 1086-1100. http://dx.doi.org/10.1108/01443579810231679

Hendry, L. C., Wilson, E., Kingsman, B. G., Worden, L., \& Mercer, A. (1992). Dynamic Planning of Resources for Make-To-Order companies. Proceedings of the eighth International conference on Computer Aided Production Engineering, 159-165.

Kingsman, B. G., Worden, L., Hendry, L. C., Mercer, A., \& Wilson, E. (1993). Integrating Production Planning in Make-To-Order Companies. Proceedings of International Conference on Managing Integrated Manufacturing, 1, 427-436.

Liberatore, M. J., \& Titus, G. J. (1996). The use of computer controlled tools by small machine shops. Journal of Small Business Management, 24(1), 55-62.

Morton, C. (1994). Becoming World Class. Macmillan Press, UK.

Muda, S., \& Caroline, L. (2002). Developing a New World Class Model for Small and Medium Sized Make-To-Order Companies. International Journal of Production Economics, 78(3), 295-310. http://dx.doi.org/10.1016/S0925-5273(01)00085-8

Muda, S., \& Caroline, L. (2003). The SHEN model for MTO SME's: a performance improvement tool. International Journal of Operations and Production Management, 23(5), 470-486. http://dx.doi.org/10.1108/01443570310471820

Random House Value Publishing. (1997). The New Webster Encyclopedic Dictionary of the English Language. Random House Value Publishing, NY.

Schonberger, R. J. (1996). World Class Manufacturing: The Next Decade. The Free Press, New York. 